\title{
Dr William Little (1810-1894) of London and cerebral palsy
}

\author{
Peter M Dunn
}

William Little was born in 1810 in Whitechapel where his father kept the Red Lion Inn. He was educated at a school near Dover and at the Jesuit College of St Omer in France. A left club-foot following poliomyelitis prevented sporting activities but he excelled academically, especially in languages.

In 1825 he was apprenticed to an apothecary, after which he studied medicine at the London Hospital, qualifying at the age of 20 and then entering general practice in London. However, after attending lectures at Guy's Hospital and University College, he decided to become a physician, visited Leyden, Leipzig, and Dresden and studied in Berlin, graduating MD in 1937. While in Germany, Stromeyer of Hanover had in 1836 successfully corrected his club-foot using subcutaneous tenotomy, and on returning to London, Little introduced this new technique, operating on a 15 year old boy in February 1837. Thus the treatment of deformities was brought into the province of surgery. Little was elected to the staff of the London Hospital in 1839 and the same year published a treatise on club-foot. ${ }^{1}$ In 1840 he founded the Orthopaedic Institution which through amalgamation became the Royal National Orthopaedic Hospital in Great Portland Street. He also had appointments to the Royal Orphan Asylum, Wanstead, the Asylum of Idiots, Reigate, and the Royal Hospital for Incurables.

Little was a good all-round physician and excelled in clinical instruction. His outstanding written work On the Nature and Treatment of the Deformities of the Human Frame ${ }^{2}$ was published in 1853. The following extract concerns his classification of congenital deformities which accords the modern concepts but ran counter to the views held at the time:

'Congenital deformities are divisible into two classes. I shall hereafter describe several distortions, of variable severity, induced, in my opinion (for the most part), by derangements of the nervous and muscular systems of the foetus, independently of any absence or deficiency of parts, characterised, also, by their capability of restoration to a surprising degree of perfection. These I shall include under the head of congenital distortions. In the last category I shall consider those in which, whatever may have been the primary interruption of normal development in the foetal parts, a total absence, incompleteness,

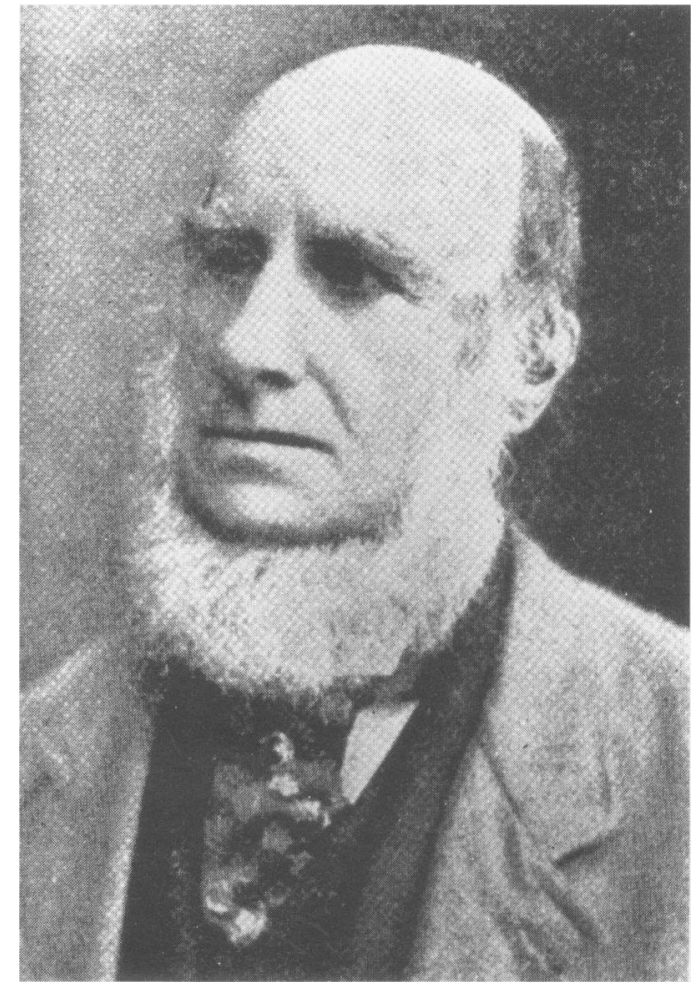

Dr William Little, 1810-1894.

or malformation of organ exists. These may be termed congenital malformations.'

Another extract from the same text illustrates Little's understanding of the nature of muscular contractures:

'Permanent muscular contraction may be induced in various ways. Long-continued repose of a limb in the flexed position has a tendency to produce a gradual shortening of the muscles on the flexed side of the articulations, so that on the attempt to resume the use of the member, a contraction of certain muscles is observed to exist, impeding the movement of the articulations. Or a spastic action of certain muscles of an articulation may arise from disorder of the nervous system, producing constant contraction of the muscles and constant distortion ... After a certain duration of contraction, from whatever cause, the muscular fibres undergo certain changes in their intimate texture, which render them incapable of voluntary elongation whenever the cause of the contraction may be removed.' 
In 1861 Little presented a most important paper to the Obstetrical Society of London. ${ }^{3}$ It contained the classic description of cerebral palsy that subsequently came to be known eponymously as Little's disease:

'The object of this communication is to show that the act of birth does occasionally imprint upon the nervous and muscular systems of the nascent infantile organism very serious and peculiar evils. When we investigate the evils in question, and their causative influences, we find that the same laws of pathology apply to diseases incidental to the act of birth as to those which originate before and after birth...

Nearly twenty years ago ... I showed that premature birth, difficult labours, mechanical injuries during parturition to head and neck, where life had been saved, convulsions following the act of birth were apt to be succeeded by a determinate affection of the limbs of the child, which I designated spastic rigidity of the limbs of new-born children...

It is obvious that the great majority of apparently stillborn infants, whose lives are saved by the attendant accoucheur, recover unharmed from that condition. I have, however, witnessed so many cases of deformity, mental and physical, traceable to causes operative at birth, that I consider the subject worthy of the notice of the Obstetrical Society. In orthopaedic practice alone, during about twenty years, I have met with probably two hundred cases of spastic rigidity from this cause...

The forms of abnormal parturition which I have observed to precede certain mental and physical derangements of the infant consisted of difficult labours - ie, unnatural presentations, tedious labours from rigidity of maternal passages or apertures, instrumental labours, labours in which turning was had recourse to, breech presentations, premature labours, and cases in which the umbilical cord had been entangled around the infant's neck or had fallen down before the head. To these abnormal forms of labour I believe ... in adding labours in which, from want of due attention immediately after birth or after expulsion from the mother, the child has been partially suffocated in the maternal secretions or under her clothing ... asphyxia neonatorum, through resulting injury to nervous centres, is the cause of the commonest contractions which originate at the moment of birth, namely, more or less general spastic rigidity, and sometimes of paralytic contraction.

The former class of affections may be described as impairment of volition, with tonic rigidity and ultimately structural shortening, in varying degrees, of a few or many of the muscles of the body. Both lower extremities are more or less generally involved. Sometimes the affection of one limb only is observed by the parent, but examination usually shows a smaller degree of affection in the limb supposed to be sound ... In most cases, after a time, owing to structural shortening of the muscles and of the articular ligaments, and perhaps to some change of forms of articular surfaces, the thighs cannot be completely abducted or extended, the knees cannot be straightened, nor can the heels be properly applied to the ground ... The muscles feel harder than natural to the age ... The muscles of speech are commonly involved ... Often during the earliest months of life deglutition is impaired ... The intellectual functions are sometimes quite unaffected, but in the majority of cases the intellect suffers - from the slightest impairment ... up to entire imbecility ... Some cases present distinct convulsive twitchings of face or limbs during first days after birth, open or suppressed convulsions, opisthotonos, or laryngismus. In some instances the persistent rigidity of muscles commences or is observed shortly after birth, in others it escapes observation until the lapse of some weeks or months...

I trust the views of the pathology of the lesions of mind and body referable to the influence of the act of birth upon the child, which I hope to have somewhat unravelled, will promote the beneficial treatment of the disorders when detected in the early stages. In the later stages, the general principles of orthopaedy, and mental training when the intellect is affected, are successfully applicable in the inverse proportion to the extent of the permanent disorganisation of the nervous centres and of peripheral structures ... treatment based upon physiology and rational therapeutics effects an amelioration surprising to those who have not watched such cases. Many of the most helpless have been restored to considerable activity and enjoyment of life. Even cases which exhibit impaired intellect may be benefited in mind and body to an unexpected extent.'

Little's observation that many of these patients are in fact intelligent, despite their appearance, and that treatment was often effective was unfortunately forgotten for many years before becoming the keystone to modern therapy.

Little married Eliza Tamplin in 1837 and they had 11 children, seven of whom survived. Two of his sons followed his interest in orthopaedic surgery, the younger, Muirhead Little, becoming first President of the British Orthopaedic Association in 1918. Although he resigned his position as physician to the London Hospital in 1863, Little continued to practise and write until increasing deafness led him to retire to Ryarsh in Kent in 1884 . There he lived until his death due to prostatic hypertrophy at the age of 84 in 1894 . He was buried at St Martin's nearby.

1 Little WJ. A treatise on the nature of club-foot and analogous distortions. London: W Jelfs, 1839.

Little WJ. On the nature and treatment of the deformities of the human frame. London: Longman, Brown, Green and human frame. Londo

3 Little WJ. On the influence of abnormal parturition, difficult labours, premature birth, and asphyxia neonatorum, on the mental and physical condition of the child, especially in relation to deformities. Transcribed from The Obstetric Society of London 1861-62; 3: 293. 